\title{
Quality of life after lower extremity amputation due to diabetic foot ulcer: the role of prosthesis-related factors, body image, self-esteem, and coping styles
}

\author{
Ozlem Kazan Kizilkurt ${ }^{1 \oplus}$, Taha Kizilkurt ${ }^{2 \oplus}$, Medine Yazici Gulec ${ }^{3}{ }^{\oplus}$, Ferzan Ergun Giynas $^{3 \oplus}$, \\ Gokhan Polat ${ }^{2}$, Onder Ismet Kilicoglu ${ }^{2}$, Huseyin Gulec $^{3 \odot}$ \\ 'Uskudar University, Department of Psychiatry, NPIstanbul Neuropsychiatry Hospital, Istanbul - Turkey \\ ${ }^{2}$ Istanbul University, Istanbul Faculty of Medicine, Department of Orthopedics and Traumatology, Istanbul - Turkey \\ ${ }^{3}$ University of Health, Sciences Erenkoy Mental Research and Training Hospital, Istanbul - Turkey
}

\begin{abstract}
Objective: The purpose of this study was to identify clinical and psychosocial factors that predict an individual's subjective quality of life after having undergone a lower limb amputation secondary to diabetic foot ulcer.

Method: The study sample comprised 65 patients who underwent amputation because of an infected diabetic foot ulcer. Short Form 36, The Trinity Amputation and Prosthesis Experience Scale, Coping Attitudes Evaluation Scale, Multidimensional Scale of Perceived Social Support, Rosenberg Self-Esteem Scale, and Amputee Body Image Scale were administered as questionnaires. Stepwise linear regression analysis was conducted to assess the factors predicting quality of life.

Results: Quality of life was negatively correlated with depression, anxiety, body image, activity limitation, and dysfunctional coping strategies and positively correlated with perceived social support, satisfaction with prosthesis, self-esteem, and problem-focused coping style. Regression analysis showed satisfaction with prosthesis and body perception, problem-focused coping strategies, dysfunctional coping strategies, and self-esteem to be the factors with the highest predictive power for the physical component of quality of life, while body perception, problem-focused, and dysfunctional coping strategies were the strongest predictors for the mental component of quality of life.

Conclusion: Impaired body image and self-esteem, less usage of problem-focused and high usage of dysfunctional coping strategies, in addition to low satisfaction with the prosthesis were the strongest predictors for poor quality of life. Factors associated with better quality of life after the amputation were investigated in this study, which may support future development of post-amputation rehabilitation strategies for lower limb amputees.
\end{abstract}

Keywords: Amputation, body image, coping strategies, diabetes, self-esteem

\section{INTRODUCTION}

Diabetic foot ulcers are often considered complications requiring long periods of challenging treatment; additionally, they may cause anxiety due to the potential necessity of amputation (1). Although the psychological status of mobile amputees is known to be better than that of diabetic foot ulcer patients, extremity amputation

How to cite this article: Kizilkurt OK, Kizilkurt T, Yazici Gulec M, Ergun Giynas F, Polat G, Kilicoglu Ol, Gulec H. Quality of life after lower extremity amputation due to diabetic foot ulcer: the role of prosthesis-related factors, body image, self-esteem, and coping styles. Dusunen Adam The Journal of Psychiatry and Neurological Sciences 2020;33:109-119.

Correspondence: Ozlem Kazan Kizilkurt, Ahmet Tevfik Ileri Street No:18, 34768 Umraniye/Istanbul - Turkey

E-mail: dr.ozlemkazan@gmail.com

Received: December 19, 2019; Revised: February 03, 2020; Accepted: March 30, 2020 
remains an important medical issue and the psychosocial adaptation of individuals after extremity amputation involves significant difficulties (2). It is generally accepted that lower extremity complications due to diabetic foot ulcer negatively affect a person's quality of life, predisposing the patient to psychiatric symptoms $(1,3,4)$. Depression and anxiety symptoms that emerge after amputation have been reported to make significant contributions to a reduced quality of life (5). In addition, it is reported that although depression and anxiety are relatively high in a period of up to 2 years post-amputation, they appear to decline thereafter to general population norms (6).

After amputation, patients can experience a distorted body image, decreased self-esteem, social isolation, and increased dependency on others (7). During the postamputation period, perceived social support, adaptation to the prosthesis, amputation type, presence of phantom and stump pain, self-esteem, and body image issues are among the factors reported to affect quality of life and psychosocial functionality significantly $(8,9)$. Different coping strategies have been shown to have different outcomes on adaptation after amputation. Problemfocused strategies are associated with positive psychosocial adaptation (10), while emotion-focused and passive strategies are associated with negative psychosocial outcomes (11).

We believe that evaluating and detecting the conditions negatively affecting individuals' quality of life after amputation are important in ensuring appropriate rehabilitation practices. Our first hypothesis was that the presence of stump and phantom pain or additional medical disease and the level and type of prosthesis would have an impact on quality of life. Secondly, we assumed that depression and anxiety scores, body image, self-esteem, coping methods, perceived social support, as well as postprosthetic activity restriction and satisfaction with prosthesis will be factors associated with quality of life. According to this hypothesis, we predicted that people with high depression and anxiety scores, distorted body image, low self-esteem, and poor perceived social support would have lower quality of life. In addition, we thought that the quality of life of patients with activity restriction after receiving the prosthesis who were not satisfied with the device would be worse off. We hypothesized that the use of problem-focused coping methods would affect the quality of life positively and the use of emotion-focused and dysfunctional coping methods would have a negative impact. A number of studies published in the past evaluated difficulties incurred in the post-amputation period. These studies typically included individuals who underwent amputation for various reasons. Considering the fact that individuals with diabetic foot ulcers are a homogeneous group with similar characteristics and a quality of life that is lower than in the normal population due to the nature of the disease, we aimed to evaluate the factors affecting the quality of life of individuals undergoing lower extremity amputation due to diabetic foot ulcer. We investigated the effects of clinical variables, perceived social support, coping attitudes, self-esteem, body image, and prosthesis adaptation on the quality of life of these patients.

\section{METHOD}

\section{Participants}

Patients being followed up at the prosthesis clinics were invited to participate in the study with a consecutive approach for 6 months. In total, 65 patients who had undergone amputation because of an infected diabetic foot ulcer were included in the study and face-to-face interviews were performed by the psychiatrists who conducted the study and orthopedic specialists who performed clinical follow-up. Measurements were administered 1-8 years (median 3 years) after fitting the prosthesis. All prostheses used by patients were of the socket type. Exclusion criteria were mental retardation, serious mental conditions that would prevent participants from being interviewed and completing the scales (e.g., serious psychotic disorder, bipolar disorder, organic mental disorder), and physical illnesses at level IV and above according to the American Society of Anesthesiologists Physical Status Classification System (12). The sample size was calculated using the G-power 3.1 program by Heinrich Heine University, Dusseldorf. A total of 64 participants were needed for a large effect size of 0.30 , a significance level of 0.05 , a verification power $(1-\beta)$ of 0.8 , and 10 predictive variables (depression, anxiety, body image, self-esteem, perceived social support, problem focused-emotional focused and dysfunctional coping mechanisms, activity restriction, satisfaction with prosthesis). Ten independent variables predicted to have an impact on quality of life were determined in the light of the earlier literature investigating factors affecting quality of life.

\section{Ethical considerations}

All participants gave written informed consent to be included in the research. Ethical approval for this study 
was obtained from the Regional Ethics Committee of the University of Health Sciences' Erenkoy Mental Research and Training Hospital, Istanbul, Turkey.

\section{Measures}

Sociodemographic variables were evaluated with a data form prepared specifically for this study.

Short Form 36 (SF-36): SF-36 was used to assess the patients' quality of life and to measure an individual's state of health based on 8 dimensions: physical function, pain, role limitations due to physical problems, general perception of health, role limitations due to emotional problems, social function, energy/vitality, and mental health. For each parameter, higher scores indicate a better health state (13). Two summary measures were further calculated from the item scores using the procedures recommended by the developers: a Physical Component (PCS) and a Mental Component (MCS) score (14). The first four dimensions of the scale form part of the PCS score and the last four dimensions comprise the MCS score (15). The reliability and validity of the scale in the Turkish population were confirmed by Kocyigit et al. (16).

The Trinity Amputation and Prosthesis Experience Scales (TAPES): TAPES is a multifactorial assessment tool for lower limb amputees fitted with prosthesis developed by Gallagher and MacLachlan (17). It is a 54-item self-report questionnaire comprising nine factor-analytically derived subscales assessing three dimensions of psychosocial adjustment (general adjustment, social adjustment, and adjustment to limitation), three dimensions of activity restriction (functional restriction, social restriction, and athletic activity restriction), and three dimensions of prosthesis satisfaction (weight satisfaction, functional satisfaction, and esthetic satisfaction). In addition, phantom and residual limb pain experiences and other medical problems unrelated to the amputation are assessed. In this study, TAPES was used to evaluate the activity restriction after prosthesis fitting, satisfaction with the prosthesis, and residual stump and phantom pain. The reliability and validity of the TAPES in the Turkish population were studied by Topuz et al. (18).

Coping Attitudes Evaluation Scale (COPE): COPE, used to assess patients' coping attitudes, was developed by Carver et al. (19). Reliability and validity of the COPE scale in the Turkish population were assessed by Agargun et al. (20). COPE is a 60-item scale with 15 subscales. Five of these 15 subscales represent problemfocused attitudes: active coping, planning, suppression of competing activities, restraint coping, and seeking of instrumental social support; 5 represent emotionfocused coping attitudes: seeking of emotional social support, positive reinterpretation, acceptance, humor, and turning to religion; and the remaining five subscales represent dysfunctional coping attitudes: focus on and venting of emotions, behavioral disregard, substance use, denial, and mental disregard (19,21). Carver et al. (19) stated that it is not appropriate to divide coping strategies into only problem-focused and emotionfocused. They criticized researchers for viewing factors other than problem-focused coping as variations on emotion-focused coping, stating that the "nature of this diversity would seem to deserve further scrutiny." In addition, while developing the COPE scale, they pointed out that some of the strategies that had been included in emotion-focused coping strategies so far were more incompatible, making it appropriate to consider them as dysfunctional coping methods (19). Therefore, in our study we evaluated coping methods under three headings as problem-focused, emotion-focused, and dysfunctional coping strategies $(22,23)$.

Multidimensional Scale of Perceived Social Support (MSPSS): The MSPSS is a 12-item scale measuring three sources of perceived support, namely, family, friends, and significant other. It is a brief, easyto-administer self-report questionnaire containing twelve items rated on a seven-point Likert-type scale with scores ranging from 'very strongly disagree' (1) to 'very strongly agree' (7). The MSPSS has proven to be psychometrically sound in diverse samples and to have good internal and test-retest reliability and robust factorial validity (24). A reliability and validity study of the MSPSS in the Turkish population was conducted by Eker (25).

Rosenberg Self-Esteem Scale (RSES): The RSES scale developed by Rosenberg (26) consists of 12 subcategories. Only the first subscale including 10 items was used in this study to assess general personal selfesteem. Each item is rated on a four-point Likert scale from 0 (strongly agree) to 3 (strongly disagree), producing a cumulative score from 0 to 30 , whereby high mean scores (computed) indicate high self-esteem (26). The reliability and validity of the scale in the Turkish population was examined by Cuhadaroglu et al. (27).

Amputee Body Image Scale (ABIS): The ABIS is a 5-point Likert-type self-assessment scale that contains 20 questions. Items in the scale query an individual's perceptions and experiences regarding her/his own body. High scores represent a distortion of body image (28). The reliability and validity of the ABIS in the Turkish population was confirmed by Safaz et al. (29). 
Patient Health Questionnaire-Somatic, Anxiety, and Depressive Symptoms (PHQ-SADS): Patients' somatic, anxiety, and depressive symptoms were assessed with the PHQ-SADS evaluation form. The PHQ-SADS is a self-report questionnaire, consisting of a Patient Health Questionnaire (PHQ-9) subscale that assesses nine domains of major depressive disorder and a General Anxiety Disorder-7 (GAD-7) subscale that rates seven basic symptoms of anxiety (30). The reliability and validity of the PHQ-SADS in the Turkish population was studied by Yazici Gulec et al. (31).

\section{Statistical Analysis}

Mean, standard deviation, median, and the lowest and highest frequency and percentage values were used for descriptive statistics and the distribution of the variables was analyzed with the Kolmogorov-Smirnov test. Factors affecting quality of life after having undergone a lower limb amputation were collected from the literature and examined in this study. The Mann-Whitney $U$ test was performed to analyze the differences in quality of life for categorical independent variables including stump pain, phantom pain, level of the prosthesis used, and comorbid medical diseases. Spearman correlation analysis was carried out to assess the relationship between qualitative independent data. Stepwise linear regression analysis was conducted to assess the factors predicting the quality of life. In all models where the MCS and PCS scores were treated as dependent variables, factors correlated with quality of life were treated as independent variables. The analyses were performed using SPSS version 22.0.

\section{RESULTS}

Sixty-five patients were included in the study, of whom $41.5 \%$ were women, $9.2 \%$ were single, $78.5 \%$ were married, $12.3 \%$ were either divorced or widowed. Of the patients, $38.5 \%$ were primary school graduates, $35.4 \%$ had completed middle school and $26.2 \%$ had a high school degree. Tables 1 and 2 report clinical data and descriptive statistics for the quality of life assessments. When the norm values in the quality of life domains were evaluated for the Turkish population (32), all domains in our study were below the average (Table 2).

Table 1: Descriptive statistics of clinical features, RSES, ABIS, MSPSS, GAD-7, PHQ-9, and TAPES scores (n=65)

\begin{tabular}{|c|c|c|c|c|c|}
\hline & Median & Mean & SD & n & $\%$ \\
\hline Age & 58.0 & 57.8 & 7.6 & & \\
\hline DM duration (Years) & 8.0 & 9.4 & 4.9 & & \\
\hline GAD-7 (Anxiety) & 6.0 & 6.0 & 4.7 & & \\
\hline PHQ-9 (Depression) & 8.0 & 8.7 & 6.8 & & \\
\hline RSES (Self-esteem) & 18.0 & 18.7 & 5.4 & & \\
\hline ABIS (Body image) & 56.0 & 56.2 & 12.1 & & \\
\hline \multicolumn{6}{|l|}{ MSPSS } \\
\hline MSPSS family & 22.0 & 21.1 & 6.1 & & \\
\hline MSPSS friends & 19.0 & 18.2 & 6.8 & & \\
\hline MSPSS others & 16.0 & 16.9 & 6.6 & & \\
\hline MSPSS total & 58.0 & 56.2 & 17.6 & & \\
\hline Prosthetic duration (Years) & 3.0 & 3.6 & 2.04 & & \\
\hline \multicolumn{6}{|l|}{ Prosthesis type } \\
\hline Below the knee & & & & 48 & 73.8 \\
\hline Above the knee & & & & 17 & 26.2 \\
\hline Having stump pain & & & & 16 & 24.6 \\
\hline Having phantom pain & & & & 17 & 26.2 \\
\hline \multicolumn{6}{|l|}{ TAPES Part 1} \\
\hline Activity restriction & 24.0 & 23.3 & 5.9 & & \\
\hline Satisfaction with the prosthesis & 35.0 & 33.3 & 8.4 & & \\
\hline
\end{tabular}


Table 2: Descriptive statistics of COPE and SF-36 scores $(n=65)$

\begin{tabular}{llll} 
& Median & Mean & \\
\hline COPE & & 56.2 & 8.5 \\
Problem-focused coping & 57.0 & 56.6 & 7.4 \\
Emotion-focused coping & 56.0 & 53.3 & 10.9 \\
Dysfunctional coping & 56.0 & & 33.1 \\
SF-36 & & 45.3 & 40.3 \\
Physical functioning & 50.0 & 38.5 & 41.7 \\
Role limitations (physical problems) & 25.0 & 36.9 & 17.5 \\
Role limitations (emotional problems) & 33.3 & 49.6 & 16.1 \\
Energy & 50.0 & 51.4 & 20.3 \\
Mental health & 52.0 & 59.8 & 20.3 \\
Social functioning & 62.5 & 65.7 \\
Pain & 67.5 & 47.8 \\
General health status & 45.0 & 3.5 \\
PCS & 39.1 & 39.3 \\
MCS & 39.6 & 39.8 & 8.9 \\
\hline
\end{tabular}

SD: Standard deviation, COPE: Coping Attitudes Evaluation Scale, SF-36: Short Form-36, PCS: Physical component summary, MCS: Mental component summary

Comparative analysis (Mann-Whitney $U$ test) was first established statistically. The patient group was divided into two subgroups according to the presence or not of phantom and stump pain. A significant difference in the PCS and MSC scores was found between groups: PCS and MCS scores in the subgroup suffering from stump and phantom pain were significantly lower than those in the patient group without such pain $(\mathrm{p}<0.01)$. Then, the patient group was divided into two subgroups according to the level of the prosthesis. PCS and MCS scores in the group having a prosthesis fitted above the knee were found to be significantly lower than scores in the group with a prosthesis fitted below the knee (transtibial amputation) $(\mathrm{p}<0.01)$. In addition, $40 \%$ of patients had comorbid medical diseases. PCS ( $p=0.011)$ and MCS $(p=0.006)$ scores showed significant differences between groups with and without a comorbid disease, and the life quality scores in the group with comorbid medical diseases were lower.

After comparative analysis, correlation analysis (Spearman analysis) was used for numerical variables. No significant correlations were found between age, duration of diabetes diagnosis, years of using prosthesis, and PCS and MCS scores ( $\mathrm{p}>0.05)$. A negative correlation was observed between PHQ-9 and also GAD-7 scores and PCS and MCS scores separately. Higher depression scores were associated with lower PCS and MCS scores $(\mathrm{p}<0.001)$. Similarly, PCS and MCS scores showed a decrease as anxiety scores increased $(\mathrm{p}<0.001)$. A negative correlation was observed between body image and quality of life, and higher ABIS scores were associated with lower PCS and MCS scores $(\mathrm{p}<0.001)$. In addition, it was found that perceived social support and self-esteem scores correlated positively with quality of life scores. Higher MSPSS scores $(\mathrm{p}<0.001)$ and RSES scores $(\mathrm{p}<0.001)$ were associated with higher PCS and MCS scores. In addition, as activity limitation increased, quality of life was negatively affected. A significant positive correlation was noted between the total score for prosthesis satisfaction and quality of life $(\mathrm{p}<0.001)$. No significant correlations were found between the emotion-focused coping score and the quality-of-life subscales ( $\mathrm{p}>0.05)$. In contrast, it was observed that quality of life scores were positively correlated with problem-focused coping strategies scores $(\mathrm{p}<0.001)$ and negatively related with dysfunctional coping strategies scores $(\mathrm{p}<0.001)$. The quality of life was better with increasing use of problemfocused coping strategies, while greater use of dysfunctional coping strategies was associated with poor quality of life (Table 3).

Independent effects of the predictors associated with quality of life according to correlation analysis were examined using a multivariate regression model. In two separate analyses with PCS and MCS scores as dependent variables, PHQ-9, GAD-7, MSPSS, ABIS, RSES, problem-focused and dysfunctional coping strategies, activity restriction, and satisfaction with prosthesis were taken as independent variables. Regression analysis showed that patients' PCS scores 
Table 3: Spearman correlation analysis between PHQ-9, GAD-7, ABIS, RSES, MSPSS, COPE subgroups, Activity restriction, Satisfaction with the prosthesis scores and PCS and MCS scores

PHQ-9 GAD-7 ABIS RSES MSPSS Problem- Emotion-

total focused focused Coping restriction with the

coping coping prosthesis

\begin{tabular}{rcccccccccc}
\hline PCS & & & & & & & & & & \\
$\mathrm{r}$ & -0.51 & -0.49 & -0.72 & 0.29 & 0.38 & 0.43 & -0.07 & -0.56 & -0.69 & 0.61 \\
$\mathrm{p}$ & $<0.001$ & $<0.001$ & $<0.001$ & $<0.001$ & $<0.001$ & $<0.001$ & 0.53 & $<0.001$ & $<0.001$ & $<0.001$ \\
MCS & & & & & & & & & & \\
$\mathrm{r}$ & -0.59 & -0.49 & -0.61 & 0.53 & 0.48 & 0.57 & 0.04 & -0.62 & -0.63 & 0.54 \\
$\mathrm{p}$ & $<0.001$ & $<0.001$ & $<0.001$ & $<0.001$ & $<0.001$ & $<0.001$ & 0.76 & $<0.001$ & $<0.001$ & $<0.001$
\end{tabular}

Spearman correlation analysis, PHQ-9: Patient Health Questionnaire-9, GAD-7: General Anxiety Disorder-7, ABIS: Amputee Body Image Scale, RSES: Rosenberg Self Esteem Scale, MSPSS: Multidimensional Scale of Perceived Social Support, PCS: Physical component summary, MCS: Mental component summary

Table 4: Stepwise multiple regression analysis model of the variables that affect MSC scores $(p<0.05)$

MCS

\begin{tabular}{|c|c|c|c|c|c|c|}
\hline & \multirow[b]{2}{*}{ B } & & \multirow[b]{2}{*}{$\mathbf{R}^{2}$} & \multirow[b]{2}{*}{ Adjusted $\mathrm{R}^{2}$} & \multirow[b]{2}{*}{$\mathbf{F}$} \\
\hline & & $\mathbf{t}$ & $\mathbf{p}$ & & & \\
\hline \multicolumn{7}{|l|}{ Model 1} \\
\hline$A B I S$ & -5.58 & -10.36 & $<0.001$ & 0.63 & 0.62 & 107.40 \\
\hline \multicolumn{7}{|l|}{ Model 2} \\
\hline ABIS & -3.71 & -6.23 & $<0.001$ & 0.73 & 0.73 & 85.63 \\
\hline Dysfunctional coping & -3.26 & -4.92 & $<0.001$ & & & \\
\hline \multicolumn{7}{|l|}{ Model 3} \\
\hline ABIS & -2.27 & -3.67 & 0.01 & 0.79 & 0.79 & 80.47 \\
\hline Dysfunctional coping & -3.67 & -6.25 & $<0.001$ & & & \\
\hline Problem focused coping & 3.09 & 4.41 & $<0.001$ & & & \\
\hline
\end{tabular}

Stepwise Multiple Regression Analysis, ABIS: Amputee Body Image Scale, MCS: Mental component summary

were significantly correlated negatively with ABIS scores $(\beta=-0.34, \mathrm{p}=0.01)$ and dysfunctional coping strategies $(\beta=-0.43, \mathrm{p}<0.001)$, positively with satisfaction with the prosthesis $(\beta=0.27, p=0.01)$, RSES scores $(\beta=0.27, \mathrm{p}<0.001)$, and problem-focused coping strategies $(\beta=0.23, \mathrm{p}=0.01)$, and the combination of these factors explained $78 \%$ of the variability of the patients' PCS scores. The regression model for the MCS scores correlated negatively with ABIS scores $(\beta=-0.32$, $\mathrm{p}=0.01)$ and dysfunctional coping strategies $(\beta=-0.47$, $\mathrm{p}<0.001)$ and positively with problem-focused coping strategies $(\beta=0.31, \mathrm{p}<0.001)$. These three significant variables explained $80 \%$ of the variance observed in the patients' MCS scores (Tables 4,5).

\section{DISCUSSION}

The present study was designed to investigate the factors affecting the quality of life of patients undergoing amputation of a lower extremity following complications arising from diabetes mellitus. Our results were consistent with those of previous studies conducted in this field (33) and revealed that both the physical and mental quality of life after lower limb amputation were reduced compared to the normal population (32). The results of our study supported our first hypothesis: The presence of stump and phantom pain, additional medical diseases, and the level of prosthetics were found to be factors related to quality of life. With regard to our second hypothesis, we have seen that many aspects are supported by the results of our study. It was observed that depression and anxiety scores, body perception, self-esteem, perceived social support, problem-focused and dysfunctional coping strategies, post-prosthetic activity restriction, and prosthetic satisfaction were related to quality of life. According to our results, the only factor that differed from our hypothesis was the use of emotion-focused coping strategies, which was not found not be related to the quality of life. Regression analysis was performed to 
Table 5: Stepwise multiple regression analysis model of the variables that affect PSC scores $(p<0.05)$

\begin{tabular}{|c|c|c|c|c|c|c|}
\hline & \multicolumn{6}{|c|}{ PCS } \\
\hline & B & $\mathbf{t}$ & $\mathbf{p}$ & $\mathbf{R}^{2}$ & Adjusted $\mathrm{R}^{2}$ & $\mathbf{F}$ \\
\hline \multicolumn{7}{|l|}{ Model 1} \\
\hline ABIS & -5.64 & -10.07 & $<0.001$ & 0.62 & 0.61 & 101.43 \\
\hline \multicolumn{7}{|l|}{ Model 2} \\
\hline$A B I S$ & -4.01 & -6.13 & $<0.001$ & 0.69 & 0.68 & 69.70 \\
\hline Dysfunctional coping & -2.83 & -3.89 & $<0.001$ & & & \\
\hline \multicolumn{7}{|l|}{ Model 3} \\
\hline ABIS & -1.90 & -2.17 & 0.03 & 0.74 & 0.73 & 57.82 \\
\hline Dysfunctional coping & -3.35 & -4.85 & $<0.001$ & & & \\
\hline Satisfaction with the prosthesis & 3.50 & 3.35 & $<0.001$ & & & \\
\hline \multicolumn{7}{|l|}{ Model 4} \\
\hline ABIS & -2.46 & -2.75 & 0.01 & 0.76 & 0.74 & 46.68 \\
\hline Dysfunctional coping & -3.30 & -4.90 & $<0.001$ & & & \\
\hline Satisfaction with the prosthesis & 3.81 & 3.69 & $<0.001$ & & & \\
\hline RSES & -2.63 & -2.05 & 0.04 & & & \\
\hline \multicolumn{7}{|l|}{ Model 5} \\
\hline ABIS & -2.41 & -2.81 & 0.01 & 0.78 & 0.76 & 42.14 \\
\hline Dysfunctional coping & -3.42 & -5.29 & $<0.001$ & & & \\
\hline Satisfaction with the prosthesis & 2.83 & 2.68 & 0.01 & & & \\
\hline Self-esteem & -4.33 & -3.10 & $<0.001$ & & & \\
\hline Problem focused coping & 2.39 & 2.57 & 0.01 & & & \\
\hline
\end{tabular}

Stepwise Multiple Regression Analysis, ABIS: Amputee Body Image Scale, RSES: Rosenberg Self Esteem Scale, PCS: Physical components summary

observe the predictive effects of these related factors, and body image, problem-focused and dysfunctional coping strategies, self-esteem, and satisfaction with the prosthesis were all observed to have a significant effect on the physical component of quality of life. Furthermore, body image and problem-focused and dysfunctional coping strategies were found to be the factors with the highest predictive power for the mental component of quality of life.

Firstly, it was observed that patients with stump and phantom pain had reduced quality of life. In the literature, in addition to studies showing that phantom pain and stump pain are not an important determinant for the quality of life (34), there are also articles arguing that these two types of pain have important effects on both physical and mental quality of life $(35,36)$. It is known that stump pain causes activity restriction as a result of negative effects on mobility and rehabilitation (6). We think that this activity restriction, which is an important factor for life quality, may explain the importance of stump pain for quality of life. In addition, phantom limb pain in some patients may gradually disappear over the course of a few months or up to one year even when untreated, but some patients suffer from phantom limb pain for decades (37). The average period of prosthesis use in our sample group was three years. We found no relationship between the duration of prosthesis use and quality of life. This result suggests that phantom pain may have an impact on the quality of life even after years have passed since fitting the prosthesis. We think that the negative effect of phantom pain on quality of life in patients with long-term prosthesis use can be evaluated as an important data point in the rehabilitation process. In our study, it was found that the patients who had undergone transtibial amputation had a better quality of life than others with higher-level amputations, and this result is compatible with the data in the literature (38). Patients with transtibial amputation level are far more mobile than those with transfemoral amputation, and rates of using crutches are higher after transfemoral amputation $(39,40)$. This is probably one of the reasons why the results of individual domains of the quality of life displayed significantly higher scores in individuals with transtibial amputations compared to patients with a higher level of amputation. 
One of the most important factors affecting functional and life quality results of amputee rehabilitation is compatible with the patient's prosthesis satisfaction (41). Patient dissatisfaction with the artificial limb can create major problems for the individual on a physical, psychological, and social level, and can directly impact health-related life quality (42). Individuals using a suitable prosthesis can regain their mobility more quickly and are more likely to adapt to the amputation successfully (43). Their selfconfidence increases as they gain functional independence and the adaptation to their social environment and working life are also affected positively (44). Similar to our work, Matsen et al. (45) found that quality of life in people with a lowerextremity amputation correlated with the comfort, function, and appearance of the prosthesis. In addition, a positive correlation has been determined in the literature between prosthesis satisfaction and quality of life and positive adaptation to extremity loss $(6,46)$. Asano et al. (5) found that problems with prosthetics after lower limb amputation are an important predictive factor for quality of life. In our study, satisfaction with the prosthesis was measured using the three subscales functional satisfaction, esthetic satisfaction, and weight satisfaction. Prosthesis satisfaction covering these three areas was found to be correlated with both physical and mental quality of life scores, but it was predictive only for the physical component. No study in the literature investigated the predictive power of quality of life for physical and mental components separately, but the importance of mobility for physical functioning has been reported in other studies $(5,47)$. When the important effect of prosthesis satisfaction on mobilization is taken into consideration, it is thought that its predictive power for the physical component may be related to this situation. Considering that a prosthesis is a means of replacing a natural limb, the importance of patient satisfaction with the device is evidently of utmost importance (7).

The loss of a limb causes emotional stress and inevitably requires examining the patient's capacity to cope with this stressful situation (48). Problemfocused coping was also found to be a major predictor of psychological and physical quality of life in our study. There are results similar to our findings in the literature. In their study with 63 individuals with lower limb amputation due to diabetes and peripheral vascular disease, Pereira et al. (49) showed that satisfaction with life was positively associated with active and planning coping. In our study, emotionfocused coping methods were found to be unrelated to the quality of life, thus not supporting our hypothesis. In contrast, a limited number of studies in the literature showed that emotion-focused and passive strategies have been associated with poor psychosocial outcomes (50). We think that the reason may be that the coping methods used in the literature are problem-oriented and emotion-oriented, while in our study, the coping assessment tool used also included dysfunctional strategies. These dysfunctional coping methods comprise some of the methods that are routinely evaluated in emotional coping methods, but are more incompatible. We think that the negative relationship of emotion-focused coping in the literature with psychosocial adjustment and quality of life may be related to these incompatible coping strategies that we determined in the dysfunctional coping strategies group. Desmond and MacLachlan (50), evaluating 3 coping strategies, namely, problem solving, seeking social support, and avoidance, found avoidance to be associated with poor psychosocial adaptation to amputation. Likewise, in our study the use of dysfunctional coping strategies was similar in effect to the non-adaptive nature of avoidance-type coping, and it was found to be a negative predictor for the physical and mental components of quality of life. The international literature has already documented that coping strategies focused on active resolution are more effective in decreasing the level of restriction in physical activities and in the adjustment to amputation $(51,52)$. Coping strategies are important not only to minimize the negative effects of lower extremity amputation but also for the amputee's psychological well-being (53). In the light of this information, which is also parallel to our results, we think that evaluating coping mechanisms as an important parameter especially in a rehabilitation program may have positive effects on patients' quality of life and general well-being.

Emotions created by breaking up the integrity of the body cause a distorted body image, leading to inadequate and negative feelings about the body and decreased self-esteem $(7,54)$. It is well known that our way of perceiving our bodies has a major effect on our social lives, psychological and physical states, and the overall quality of our lives (55). When individuals perceptions of their bodies are distorted after amputation, they experience greater difficulties carrying out the bodily movements required for daily activities and struggle to accept their new body image; this can 
lead to rejection of the prosthesis and difficulties in functional adaptation (56). It has been stated that the deterioration in the body image perception of the amputated person may affect their lives physically, socially, and psychologically, as they do not conform to the esthetic perception accepted by the majority of social media users and society (57). Holzer et al. (9) found that body image was distorted in patients who had undergone amputation, and the physical and mental components of their quality of life was negatively affected. In our study, it was observed that the perception of body image was an important predictive factor for both physical and mental quality of life. Similar to our results, Rybarczyk et al. (8) stated that body image is an independent predictor of quality of life. Helping amputees to integrate into society successfully requires their amputation-associated body image distortions to be addressed during rehabilitation, and understanding the impact of body image is critical for appropriate rehabilitation interventions (8).

Studies have also indicated that self-perception and evaluating one's body are a significant source of selfesteem (58). Although many studies show that selfesteem decreases after amputation $(7,28)$, few studies trace the relationship between self-esteem and quality of life. One study investigating the relationship between self-esteem and quality of life reported a weak correlation between these two variables (9). In contrast, we observed that decreased self-esteem was a significant predictor of a poor physical component of quality of life. In a study with patients undergoing mastectomy, a procedure that similarly leads to the feeling of mutilation of the body, self-esteem was also reported to be decreased, which was a significant predictive factor for impaired health-associated quality of life (59). Cognitive Behavioral Therapy (CBT) was introduced as a method to increase individuals' adaptation to chronic health states. CBT is advocated in helping patients recognize and adjust their distorted thinking patterns and nonproductive behaviors by focusing on their emotional, cognitive, and behavioral responses (60). Studies have shown that CBT is effective in improving self-esteem, body image, and quality of life among patients with chronic diseases $(61,62)$. A recent study examining the beneficial effect of CBT on self-esteem and quality of life among elder amputees demonstrated that selfesteem and life quality significantly improved among these individuals (60).

There are some limitations of our study. First of all, due to its cross-sectional design, it was not possible to establish cause-effect relationships. There was no longitudinal follow-up before and after amputation and non-amputee diabetic foot patients were not included in the study as a comparison group. Secondly, in parallel with amputation, the effect of diabetes mellitus itself on the quality of life should be taken into consideration, as all negative effects on quality of life are unlikely to be attributable to the amputation. Comorbid medical and psychiatric disorders were not considered as a confounding factor on outcome. Eventually, when this study examined the effect of medical diseases and psychiatric burdens such as depression, anxiety, and somatization on the outcome, it was observed that these burdens had no predictive power on the outcome.

In conclusion, the results of our study emphasize the significance of multiple physical and psychosocial aspects in the successful adaptation of patients after amputation. This study investigated the variables affecting the quality of life of individuals in orthopedic practice, applying a biopsychosocial approach. It has shown that patients' existing schemas of coping styles, self-esteem, and body perception have a greater impact on the outcome than their physical variables and psychological burdens such as depression and anxiety. Furthermore, the importance of multidisciplinary evaluation of patients is evident, both during amputation, which is a traumatic process, and during rehabilitation. We suggest that rehabilitation after amputation should be a multifactorial process including physical functional adaptation and psychosocial schemes.

\begin{tabular}{|c|c|c|}
\hline \multicolumn{2}{|c|}{ Contribution Categories } & \multirow{2}{*}{$\begin{array}{l}\text { Author Initials } \\
\text { O.K.K., T.K., M.Y.G., F.E.G., } \\
\text { G.P., I.O.K., H.G. }\end{array}$} \\
\hline \multirow{3}{*}{ Category 1} & Concept/Design & \\
\hline & Data acquisition & T.K., G.P. \\
\hline & Data analysis/Interpretation & O.K.K., H.G. \\
\hline \multirow{2}{*}{ Category 2} & Drafting manuscript & O.K.K., T.K., F.E.G., G.P. \\
\hline & Critical revision of manuscript & M.Y.G., I.O.K., H.G. \\
\hline Category 3 & Final approval and accountability & $\begin{array}{l}\text { O.K.K., T.K., M.Y.G., F.E.G., } \\
\text { G.P., O.I.K., H.G. }\end{array}$ \\
\hline \multirow{2}{*}{ Other } & Technical or material support & N/A \\
\hline & Supervision & $\mathrm{N} / \mathrm{A}$ \\
\hline
\end{tabular}

Ethics Committee Approval: Ethical approval for this study was obtained from the Regional Ethics Committee of the University of Health Sciences' Erenkoy Mental Research and Training Hospital, Istanbul, Turkey.

Informed Consent: Written informed consent of all patients was obtained.

Peer-review: Externally peer-reviewed.

Conflict of Interest: There in no conflict of interest.

Financial Disclosure: There is no any financial support. 


\section{REFERENCES}

1. Ragnarson Tennvall G, Apelqvist J. Health-related quality of life in patients with diabetes mellitus and foot ulcers. J Diabetes Complications 2000; 14:235-241.

2. Carrington AL, Mawdsley SK, Morley M, Kincey J, Boulton AJ. Psychological status of diabetic people with or without lower limb disability. Diabetes Res Clin Pract 1996; 32:19-25.

3. Willrich A, Pinzur M, McNeil M, Juknelis D, Lavery L. Health related quality of life, cognitive function, and depression in diabetic patients with foot ulcer or amputation. A preliminary study. Foot Ankle Int 2005; 26:128-134.

4. Boutoille D, Féraille A, Maulaz D, Krempf M. Quality of life with diabetes-associated foot complications: comparison between lower-limb amputation and chronic foot ulceration. Foot Ankle Int 2008; 29:1074-1078.

5. Asano M, Rushton P, Miller WC, Deathe BA. Predictors of quality of life among individuals who have a lower limb amputation. Prosthet Orthot Int 2008; 32:231-243.

6. Horgan O, MacLachlan M. Psychosocial adjustment to lowerlimb amputation: a review. Disabil Rehabil 2004; 26:837-850.

7. Grossman EF. The Gestalt approach to people with amputations. J Appl Rehabil Couns 1990; 21:16-19.

8. Rybarczyk B, Nyenhuis D, Nicholas JJ, Cash SM, Kaiser J. Body image, perceived social stigma, and the prediction of psychosocial adjustment to leg amputation. Rehabil Psychol 1995; 40:95-110.

9. Holzer LA, Sevelda F, Fraberger G, Bluder O, Kickinger W, Holzer G. Body image and self-esteem in lower-limb amputees. PLoS One 2014; 9:e92943.

10. Dunn DS. Well-being following amputation: Salutary effects of positive meaning, optimism, and control. Rehabil Psychol 1996; 41:285-302.

11. Livneh H, Antonak RF, Gerhardt J. Psychosocial adaptation to amputation: the role of sociodemographic variables, disabilityrelated factors and coping strategies. Int J Rehabil Res 1999; 22:21-31.

12. Daabiss M. American Society of Anaesthesiologists physical status classification. Indian J Anaesth 2011; 55:111-115.

13. Ware JE Jr, Sherbourne CD. The MOS 36-item short-form health survey (SF-36). I. Conceptual framework and item selection. Med Care 1992; 30:473-483.

14. Ware JE, Jr, Kosinski MA, Keller SD. SF-36 physical and mental health summary scales: a User's Manual. Fifth ed., Boston: MA Health Assessment Lab, New England Medical Center, 1994.

15. Ware JE Jr. SF-36 health survey update. Spine (Phila Pa 1976) 2000; 25:3130-3139.

16. Kocyigit H, Aydemir O, Fisek G, Olmez N, Memis AK. Reliability and validity of the Short Form 36, Turkish version (KF-36). Ilac ve Tedavi Dergisi 1999; 12:102-106. (Turkish)

17. Gallagher P, MacLachlan M. Development and psychometric evaluation of the Trinity Amputation and Prosthesis Experience Scales (TAPES). Rehabil Psychol 2000; 45:130-154.
18. Topuz S, Ulger O, Yakut Y, Gul Sener F. Reliability and construct validity of the Turkish version of the Trinity Amputation and Prosthetic Experience Scales (TAPES) in lower limb amputees. Prosthet Orthot Int 2011;35:201-206.

19. Carver CS, Scheier MF, Weintraub JK. Assessing coping strategies: a theoretically based approach. J Pers Soc Psychol 1989; 56:267283.

20. Agargun MY, Besiroglu L, Kiran UK, Ozer OA, Kara H. The psychometric properties of the COPE inventory in Turkish sample: a preliminary research. Anadolu Psikiyatri Derg 2005; 6:221.

21. Carver CS, Scheier MF. Situational coping and coping dispositions in a stressful transaction. J Pers Soc Psychol 1994; 66:184-195.

22. Cooper C, Katona C, Orrell M, Livingston G. Coping strategies and anxiety in caregivers of people with Alzheimer's disease: the LASER-AD study. J Affect Disord 2006; 90:15-20.

23. Coolidge FL, Segal DL, Hook JN, Stewart S. Personality disorders and coping among anxious older adults. J Anxiety Disord 2000; 14:157-172.

24. Zimet GD, Dahlem NW, Zimet SG, Farley GK. The multidimensional scale of perceived social support. J Pers Assess 1988;52:30-41.

25. Eker D, Arkar H, Yaldiz H. Factorial Structure, Validity, and Reliability of Revised Form of the Multidimensional Scale of Perceived Social Support. Turk Psikiyatri Derg 2001; 12:17-25. (Turkish)

26. Rosenberg M. Society and the Adolescent Self-Image. First ed., Princeton, NJ.:Princeton University Press, 1965.

27. Cuhadaroglu F. Self-esteem in Adolescents. Specialization Thesis, Hacettepe University Medical Faculty Department of Psychiatry, Ankara. 1986. (Turkish)

28. Breakey JW. Body image: the lower-limb amputee. JPO J Prosthetics Orthot 1997; 9:58-66.

29. Safaz I, Yilmaz B, Goktepe AS, Yazicioglu K. Turkish version of the amputee body image scale and relationship with quality of life. Bulletin Clin Psychopharmacol 2010; 20:79-83.

30. Kroenke K, Spitzer RL, Williams JB. The PHQ-9: validity of a brief depression severity measure. J Gen Intern Med 2001; 16:606-613.

31. Yazici Gulec M, Gulec H, Simsek G, Turhan M, Aydin Sunbul E. Psychometric properties of the Turkish version of the Patient Health Questionnaire-Somatic, Anxiety, and Depressive Symptoms. Compr Psychiatry 2012; 53:623-629.

32. Demiral Y, Ergor G, Unal B, Semin S, Akvardar Y, Kivircik B, et al. Normative data and discriminative properties of short form 36 (SF-36) in Turkish urban population. BMC Public Health 2006; 6:247.

33. Hagberg K, Brånemark R. Consequences of non-vascular transfemoral amputation: a survey of quality of life, prosthetic use and problems. Prosthet Orthot Int 2001; 25:186-194.

34. Sinha R, van den Heuvel WJ, Arokiasamy P. Factors affecting quality of life in lower limb amputees. Prosthet Orthot Int 2011; 35:90-96. 
35. Arena JG, Sherman RA, Bruno GM, Smith JD. The relationship between situational stress and phantom limb pain: cross-lagged correlational data from six month pain logs. J Psychosom Res 1990; 34:71-77.

36. van der Schans CP, Geertzen JH, Schoppen T, Dijkstra PU. Phantom pain and health-related quality of life in lower limb amputees. J Pain Symptom Manage 2002; 24:429-436.

37. Kaur A, Guan Y. Phantom limb pain: A literature review. Chin J Traumatol 2018; 21:366-368.

38. Knežević A, Salamon T, Milankov M, Ninković S, Jeremić Knežević $\mathrm{M}$, Tomašević Todorović S. Assessment of quality of life in patients after lower limb amputation. Med Pregl 2015; 68:103-108.

39. Burger H, Marincek C, Isakov E. Mobility of persons after traumatic lower limb amputation. Disabil Rehabil. 1997; 19:272277.

40. Raya MA, Gailey RS, Fiebert IM, Roach KE. Impairment variables predicting activity limitation in individuals with lower limb amputation. Prosthet Orthot Int 2010; 34:73-84.

41. Schürmann T, Beckerle P, Preller J, Vogt J, Christ O. Theoretical implementation of prior knowledge in the design of a multi-scale prosthesis satisfaction questionnaire. Biomed Eng Online 2016; 15:143.

42. Millstein S, Bain D, Hunter GA. A review of employment patterns of industrial amputees--factors influencing rehabilitation. Prosthet Orthot Int 1985; 9:69-78.

43. Sansam K, Neumann V, O'Connor R, Bhakta B. Predicting walking ability following lower limb amputation: a systematic review of the literature. J Rehabil Med 2009; 41:593-603.

44. Fernández A, Isusi I, Gómez M. Factors conditioning the return to work of upper limb amputees in Asturias, Spain. Prosthet Orthot Int 2000; 24:143-147.

45. Matsen SL, Malchow D, Matsen FA 3rd. Correlations with patients' perspectives of the result of lower-extremity amputation. J Bone Joint Surg Am 2000; 82:1089-1095.

46. Akarsu S, Tekin L, Safaz I, Göktepe AS, Yazicioğlu K. Quality of life and functionality after lower limb amputations: comparison between uni- vs. bilateral amputee patients. Prosthet Orthot Int 2013; 37:9-13.

47. Deans SA, McFadyen AK, Rowe PJ. Physical activity and quality of life: A study of a lower-limb amputee population. Prosthet Orthot Int 2008; 32:186-200.

48. Copuroglu C, Ozcan M, Yilmaz B, Gorgulu Y, Abay E, Yalniz E. Acute stress disorder and post-traumatic stress disorder following traumatic amputation. Acta Orthop Belg 2010; 76:90-93.
49. Pereira MG, Ramos C, Lobarinhas A, Machado JC, Pedras S. Satisfaction with life in individuals with a lower limb amputation: The importance of active coping and acceptance. Scand J Psychol 2018; 59:414-421.

50. Desmond DM, MacLachlan M. Coping strategies as predictors of psychosocial adaptation in a sample of elderly veterans with acquired lower limb amputations. Soc Sci Med 2006; 62:208-216.

51. Andersson M, Deighan F. Coping strategies in conjunction with amputation: A literature study. Thesis, Division for Health and Caring Sciences, Karlstads University, Sweden, 2006.

52. Couture M, Desrosiers J, Caron CD. Coping with a lower limb amputation due to vascular disease in the hospital, rehabilitation, and home setting. ISRN Rehabil 2012; 179878.

53. Oaksford K, Frude N, Cuddihy R. Positive coping and stressrelated psychological growth following lower limb amputation. Rehabil Psychol 2005; 50:266-277.

54. Parkes CM. Components of the reaction to loss of a lamb, spouse or home. J Psychosom Res 1972; 16:343-349.

55. Adamson PA, Doud Galli SK. Modern concepts of beauty. Curr Opin Otolaryngol Head Neck Surg 2003; 11:295-300.

56. Deusen J Van. Body image of non-clinical and clinical populations of men: a literature review. Occup Ther Ment Heal 1996; 13:3757.

57. Ching S, Thoma A, McCabe RE, Antony MM. Measuring outcomes in aesthetic surgery: a comprehensive review of the literature. Plast Reconstr Surg 2003; 111:469-480.

58. Goldenberg JL, McCoy SK, Pyszczynski T, Greenberg J, Solomon $\mathrm{S}$. The body as a source of self-esteem: the effect of mortality salience on identification with one's body, interest in sex, and appearance monitoring. J Pers Soc Psychol 2000; 79:118-130.

59. Mustian KM, Katula JA, Gill DL, Roscoe JA, Lang D, Murphy K. Tai Chi Chuan, health-related quality of life and self-esteem: a randomized trial with breast cancer survivors. Support Care Cancer 2004; 12:871-876.

60. Alavi M, Molavi H, Molavi R. The impact of cognitive behavioral therapy on self-esteem and quality of life of hospitalized amputee elderly patients. Nurs Midwifery Stud 2017; 6:162-167.

61. Didarloo A, Alizadeh M. Health-Related Quality of Life and its Determinants Among Women With Diabetes Mellitus: A CrossSectional Analysis. Nurs Midwifery Stud. 2016; 5:e28937.

62. Kiani J, Pakizeh A, Ostovar A, Namazi S. Effectiveness of cognitive behavioral group therapy (CBGT) in increasing the self esteem \& decreasing the hopelessness of $\beta$-thalassemic adolescents. Iran South Med J 2010; 13:241-252. (Persian) 